\title{
Influence of Control and Finishing of Internal Blinds on the Cooling Energy Consumption of Buildings
}

\author{
Mateus Vinícius Bavaresco ${ }^{1}$, Matheus Soares Geraldi ${ }^{1}$, Bruna Faitão Balvedi ${ }^{1}$, Enedir Ghisi ${ }^{1}$ \\ ${ }^{1}$ Federal University of Santa Catarina, Florianópolis, Brazil
}

\begin{abstract}
This study presents a simulation-based approach to investigate the influence of control and finishing of internal blinds on building performance. Three control patterns were combined with two finishings of internal blinds in spaces with different solar orientations, windowto-wall ratios and width-to-depth ratios. Building performance simulations were conducted using the EnergyPlus computer programme. Results showed that both control and finishing of internal blinds impact the performance of buildings. This outcome supports the belief that both designers and occupants must know how systems affect the energy consumption of buildings to boost their performance throughout the life cycle.
\end{abstract}

\section{Introduction}

Occupant behaviour is one of the driving factors that affect the energy consumption in buildings (Yoshino et al., 2017). The actions that people take inside their buildings impact both indoor comfort indexes and energy consumption, which is highly denoted in the literature (Yan et al., 2015; Gaetani et al., 2016; Hong et al., 2016; Hong et al., 2017). In this regard, there is a need to understand how people behave (considering the factors that trigger human-building interactions) and to what extent those behaviours modify indoor conditions and energy consumption in buildings.

Most systems may be operated by occupants during working hours (e.g., windows, internal blinds, HVAC systems, etc.). Adjustments of internal blinds are important for the building energy performance as they block direct sunlight and solar radiation during the cooling seasons as well as allow solar radiation to enter the building if necessary (Kuhn et al., 2001). Therefore, understanding the triggers of human-blind interactions is important to estimate the impact of such actions on the building performance; which is useful for better estimations of energy consumption during the building design phase.

O'Brien et al. (2013) reviewed the literature to better comprehend the manual adjustment of internal blinds in office buildings. Many occupants stated that the lack of adjustments of internal blinds was due to difficulty or great effort needed to reach the blinds. Moreover, they stated that occupants of shared spaces tend to be less active to prevent disturbing their colleagues. Considering the Brazilian reality - where most of the building systems are manually controlled - it is vital to understand how different control patterns affect indoor environmental conditions and energy consumption. In addition to the control patterns, the literature supports that different finishings of internal blinds may also influence their performance. In this regard, Frontini and Kuhn (2012) found that the properties of internal blinds can affect the operative temperature in offices. The authors concluded that internal blinds with low emissivity can reduce the operative temperature by nearly $1 \mathrm{~K}$ at distances up to 0.5 $\mathrm{m}$ from the façade. Furthermore, Kirimtat et al. (2016) conducted a literature review on simulation modelling for shading devices and concluded that future projects should determine the proper shading devices for reducing the cooling load of buildings in hot climate regions. Literature supports the concept of building design robustness as well (Buso et al., 2015; O'Brien, 2013), which emphasizes that some building characteristics may reduce the impact of occupant behaviour on energy consumption. As shown by O'Brien and Gunay (2015), robust design is not about changing occupant behaviour, but rather changing the indoor conditions that are related to human-building interactions. Therefore, there is the need to find the influence of both controls and finishings of internal blinds on the energy performance of buildings with different characteristics. Awareness of the impact of these associations provides background to stakeholders to boost building performances in the design and operation phases. Considering these challenges, the objective of this study is to test the influence of different controls and finishings of internal blinds associated with variations of building characteristics. The outcomes presented by Bavaresco and Ghisi (2018) regarding occupant self-reported times for adjusting internal blinds in an office building located in Florianópolis, southern Brazil, were used to create control patterns of internal blinds. The study relied on questionnaire application and many triggers can be used for controlling internal blinds both in building simulation and automation approaches. Thus, evidence found in the literature was combined to that found in situ and three scenarios for blind adjustments were established. A timebased control created according to the most frequent occupant self-reported time of internal blind adjustments. This was compared with two automation scenarios based on both occupant statements and literature review (thresholds for the internal blind adjustments were based on literature review). 


\section{Method}

The method is based on data from a questionnaire application conducted by Bavaresco and Ghisi (2018) in an office building located in Florianópolis, regarding human-blind interactions. The questionnaire is available in our previously mentioned work. A printed version of the questionnaire was delivered to each occupant during a typical summer month (March 2016). The research purposes were individually explained to the users and the questionnaire was returned the following day. A total of 164 users (out of 200) answered the questionnaire (82\%). Information about how often people adjust blinds over time and which factors trigger blind adjustments were analysed to set the control patterns. Two finishings of internal blinds were tested: fabric and metal. The different controls and finishings of blinds were associated with different building characteristics in the computer simulations. Results highlighted the influence of such combinations on the cooling energy consumption and the amount of time that the setpoint temperature is not met during working hours. Figure 1 shows the method flowchart.

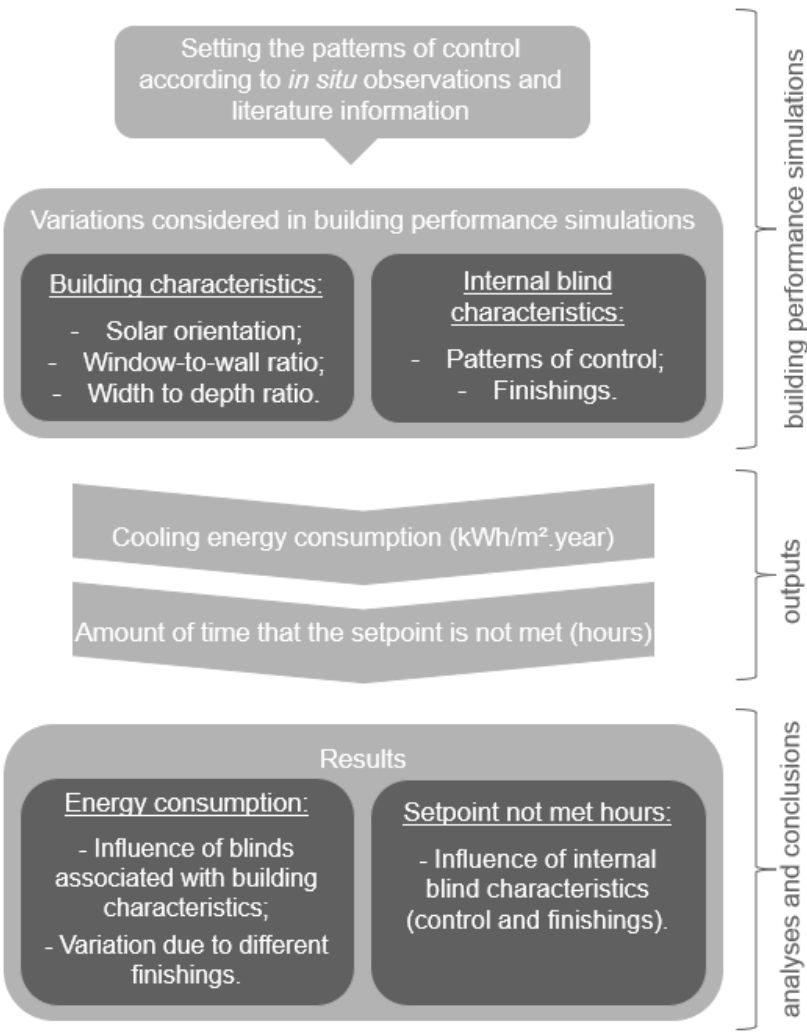

Figure 1: Flowchart of the method.

\section{Controls and finishings of internal blinds}

Different controls and finishings of internal blinds were tested to investigate the influence of those strategies combined with building characteristics such as solar orientation, window-to-wall ratio and width-to-depth ratio.

The results from the application of questionnaires showed that occupants tend to open internal blinds in the morning upon arrival, regardless of the orientation - presented by
Haldi and Robinson (2010) as well. Variations were found in the self-reported time of closing blinds for different solar orientations as shown in Table 1. Gunay et al. (2013) conducted a literature review on adaptive occupant behaviours in offices and found similar outcomes regarding the influence of façade orientation on the adjustment of internal blinds. Besides that, occupants reported that the main causes for closing internal blinds are excessive solar radiation and high internal temperature.

Table 1: Relation between orientation and the main period when internal blinds are closed.

\begin{tabular}{|c|c|}
\hline Solar orientation & $\begin{array}{c}\text { Main period when internal blinds } \\
\text { are closed }\end{array}$ \\
\hline North & In the afternoon \\
\hline South & Mostly open throughout the year \\
\hline East & In the morning \\
\hline West & In the afternoon \\
\hline
\end{tabular}

By combining insights from the field evaluation with literature information, three control patterns of internal blinds were created. Internal blind closing was based on three scenarios:

- Time-dependent control based on the occupant selfreported main times for opening and closing internal blinds (Bavaresco and Ghisi, 2018; Haldi and Robinson, 2010);

- Temperature-based control, setting $24^{\circ} \mathrm{C}$ for both turning on the HVAC and closing the internal blinds (Haldi and Robinson, 2008);

- Solar-radiation based control, as shown by Mahdavi et al. (2008) to be related with the closing of blinds when vertical global radiation on the façade is equal to or greater than $200 \mathrm{~W} / \mathrm{m}^{2}$.

Besides the three control patterns of internal blinds, different finishings were also compared. Light-coloured fabric and vertical internal blinds were modelled according to the thermal properties used on the DIVA-forRhino plug-in (Reinhart and Niemasz, 2018); and whitepainted metallic blinds were modelled according to InputOutput References provided in the EnergyPlus documentation (DOE, 2018). The main differences between them are that the fabric blind has a low thermal conductivity $(0.9 \mathrm{~W} / \mathrm{m} . \mathrm{K})$ compared to the metallic blind conductivity $(44.9 \mathrm{~W} / \mathrm{m} . \mathrm{K})$, and the metallic blind is $100 \%$ opaque to solar radiation.

\section{Characteristics of simulated spaces}

Individual thermal zones with a single-glazed façade were simulated. Solar orientation was varied from north, south, east, and west. Three window-to-wall ratios were considered: $20 \%, 50 \%$ and $80 \%$. And two cases of widthto-depth ratios were tested - 1:1 (10.00 $\mathrm{m} \times 10.00 \mathrm{~m})$ and $1: 2(10.00 \mathrm{~m} \times 20.00 \mathrm{~m})$. In all cases, floor-to-ceiling height was $2.80 \mathrm{~m}$.

Besides the glazed façade, all the other surfaces were adiabatic. Regarding the glazed façade, the thermophysical properties of wall and glazing were determined according to the reference model for office buildings of the Brazilian Regulation for Energy 
Efficiency of Buildings (CB3E, 2017). The internal thermal loads of the spaces were configured according to this Regulation as well. All the internal loads and thermal properties of constructions are shown in Tables 2 and 3, respectively.

Table 2: Internal loads according to the reference model for office buildings of the Brazilian Regulation.

\begin{tabular}{|c|c|}
\hline Internal loads & Value \\
\hline Equipment $\left(\mathrm{W} / \mathrm{m}^{2}\right)$ & 9.70 \\
\hline Light $\left(\mathrm{W} / \mathrm{m}^{2}\right)$ & 8.90 \\
\hline People $\left(\mathrm{m}^{2} /\right.$ person$)$ & 10.00 \\
\hline
\end{tabular}

Table 3: Thermal properties of building surfaces according to the reference model for office buildings of the Brazilian Regulation.

\begin{tabular}{|c|c|}
\hline Envelope thermal properties & Value \\
\hline Wall thermal transmittance $\left(\mathrm{W} / \mathrm{m}^{2} . \mathrm{K}\right)$ & 2.39 \\
\hline Wall solar absorptance $($ dimensionless $)$ & 0.50 \\
\hline Wall thermal capacity $\left(\mathrm{kJ} / \mathrm{m}^{2} . \mathrm{K}\right)$ & 150.00 \\
\hline Glass thermal transmittance $\left(\mathrm{W} / \mathrm{m}^{2} . \mathrm{K}\right)$ & 5.70 \\
\hline Glass solar heat gain coefficient $($ dimensionless) & 0.82 \\
\hline Glass thickness $(\mathrm{mm})$ & 6.00 \\
\hline
\end{tabular}

\section{Energy Performance Simulations}

Simulations were performed using the EnergyPlus computer programme. The convective algorithm adopted was the Thermal Analysis Research Program (TARP) and the heat balance algorithm was the Conduction Transfer Function (CTF).

The TRY weather file for Florianópolis (located at the latitude $27^{\circ} 36^{\prime}$ South) created by the National Institute of Meteorology (INMET) was used. It is available for download on the LabEEE website (LabEEE, 2016). The use of this weather file is required by the Brazilian Regulation for Energy Efficiency of Buildings (CB3E, 2017).

Occupancy schedules were defined from 08:00 to 18:00, with a break from 12:00 to 14:00, on weekdays. During the break, occupancy was configured as $50 \%$ of total occupancy $\left(10 \mathrm{~m}^{2} /\right.$ person$)$. No occupancy was defined over the weekends and national holidays. Schedules for equipment and lighting were based on these patterns of occupancy.

The mini-split HVAC system was used on the simulations to calculate the cooling energy consumption of the models. A cooling setpoint temperature equal to $24^{\circ} \mathrm{C}$ was used throughout the year and a coefficient of performance equal to $3.24 \mathrm{~W} / \mathrm{W}$ was configured to meet the minimum requirement for energy efficiency label A (INMETRO, 2018). Air renewal rate of $27 \mathrm{~m}^{3} / \mathrm{h} /$ person was used according to Resolution \#9 of the Brazilian Health Regulatory Agency (ANVISA, 2003). The sizing of HVAC system was based on the summer design day (February 21 $1^{\text {st }}$ ) commonly used in Florianópolis (maximum dry-bulb temperature: $31.95^{\circ} \mathrm{C}$; daily dry-bulb temperature range: $6.90^{\circ} \mathrm{C}$; wet-bulb at maximum drybulb: $25.30^{\circ} \mathrm{C}$ ).

\section{Analyses of simulation results}

Two main simulation outputs were analysed in this study: cooling energy consumptions and the amount of time that the setpoint temperature $\left(24^{\circ} \mathrm{C}\right)$ is not met during working hours. For the latter, a tolerance of $1^{\circ} \mathrm{C}$ from the setpoint was configured in the OutputControl:ReportingTolerances of the EnergyPlus object.

Firstly, cooling energy consumptions were analysed according to building characteristics to find relations between them and the controls of internal blinds. Further analysis investigated the influence of different finishings of internal blinds on both cooling consumption and variations on the amount of time that the setpoint temperature is not met. For the former, comparisons were made case-by-case as shown in Figure 2. In other words, similar cases were compared considering the change in the finishing of the internal blind from fabric to metal. Results are presented as percentage reductions of cooling energy consumption. For the analysis of the amount of time that the setpoint temperature is not met during working hours, all the cases with blinds were compared to similar cases without blinds. The results are presented according to the percentage of reduction in this output compared to the "without blinds" scenario.

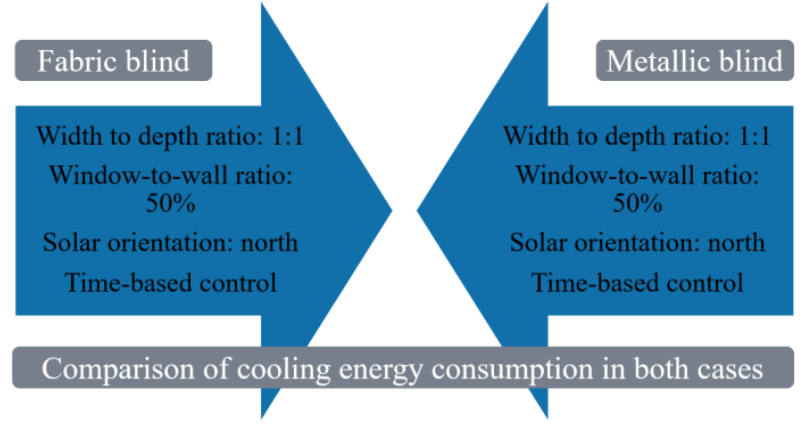

Figure 2: Comparison of finishings of internal blinds regarding cooling energy consumption.

\section{Results}

\section{Impact of control of blinds on the cooling energy consumption}

Based on occupant self-reported interactions with internal blinds, a time-based control was created and compared with two automation approaches: control triggered by either solar radiation or temperature. Likewise, a scenario without internal blinds was tested for comparison purposes.

Figure 3 shows the cooling energy consumption related to each control according to the building characteristics tested - solar orientation, window-to-wall ratio and width-to-depth ratio. As expected, the cooling energy consumption is strongly related to building characteristics. Higher consumptions were found in spaces more affected by external conditions: north and east-oriented spaces with bigger window-to-wall ratios and width-to-depth of 1:1. 

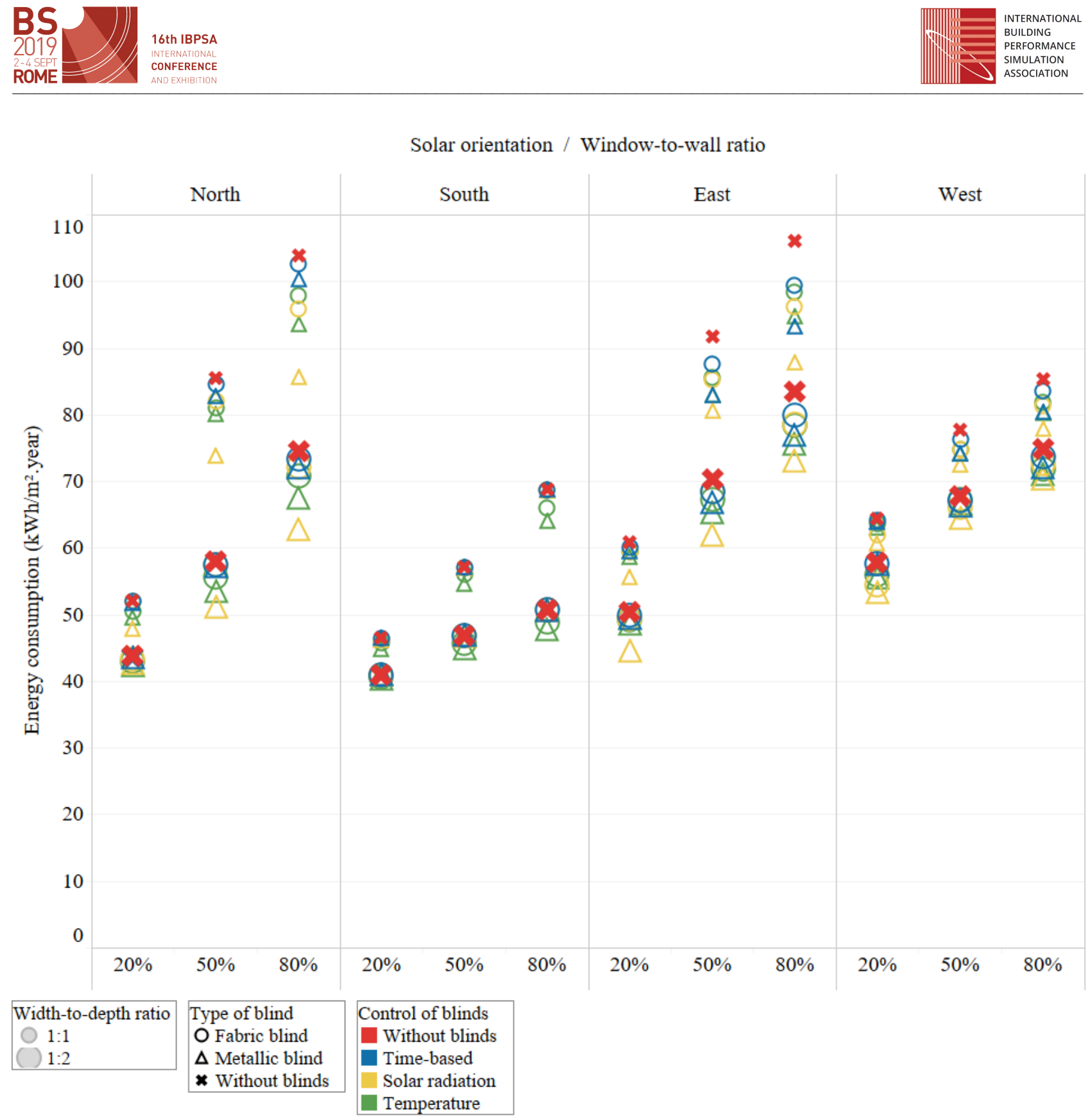

Figure 3: Relation between cooling energy consumption and building characteristics (solar orientation, window-towall and width-to-depth ratios) according to different controls of blinds.

North and east-oriented spaces had greater cooling energy consumptions in relation to west-oriented ones due to the incidence of direct solar radiation during working hours. Thus, lower energy consumption and variations were found when different controls of blinds were used in westoriented spaces; even so, solar-radiation-based control still plays an important role. By investigating the content of the weather file used in the simulations, it was found that the solar radiation index is lower for the west compared to both north and east orientations. This may be an inconsistency in the weather file available for Florianópolis.

Regarding the width-to-depth ratios, Ghisi et al. (2005) found similar outcomes about their influence on the building energy consumption. The authors showed that the energy consumption decreases as the width of the room decreases and its depth increases. Thus, as the spaces with width-to-depth ratio of $1: 1$ consume more energy to cool the air, they are more susceptible to improve their performance when different controls of internal blinds are used (e.g., cooling energy consumption of east-oriented spaces with a window-to-wall ratio equal to $80 \%$ varied from 87 to $105 \mathrm{kWh} / \mathrm{m}^{2}$.year - about $21 \%$ variation). Although less impactful, spaces with smaller window-to-wall ratios and width-to-depth ratio of 1:2 were influenced by the controls of internal blinds as well (e.g., cooling energy consumption of east-oriented spaces with a window-to-wall ratio equal to $20 \%$ varied from 44 to $50 \mathrm{kWh} / \mathrm{m}^{2}$.year - about $13 \%$ variation). As they have less glazed area in the envelope, different controls of blinds have a smaller influence on the indoor conditions and energy consumptions. This building-dependent impact of internal blind control follows the concept of robustness of building design proposed by Buso et al. (2015) and occupant-proof buildings shown by O'Brien (2013). In this case, buildings that are less affected by 
external conditions are more robust against variation of internal blind adjustments.

Among the strategies tested, solar-radiation-based control was found as the main reducer of cooling energy consumption on north, east and west-oriented spaces. This outcome is valid for all the window-to-wall and width-todepth ratios. As solar radiation index is lower for the west compared to both north and east orientations, the influence of this control is less impactful in west-oriented spaces. An opposing outcome was found for southoriented spaces, where the direct solar radiation does not play an important role at the latitude of Florianópolis. In this case, temperature-based control was found as the main responsible for reducing cooling energy consumptions. Although not being the most impactful strategy, temperature-based control reduced cooling energy consumption in all cases; in most results, this strategy is more effective compared to time-based controls.

In general, time-based control was the less impactful strategy regarding the reduction of cooling energy consumption. However, this outcome is due to the rules created according to occupant responses to the questionnaire. Time-based control does not influence the cooling energy consumption of south-oriented spaces because occupants stated that internal blinds remain mostly open throughout the year in this orientation. It is important to note that southern façades are affected by direct solar radiation mainly in summer during unoccupied hours - beginning of the morning and end of the afternoon. Overall, time-based control is more effective for east and west-oriented spaces, where the times for internal blind closing coincide with the incidence of direct solar radiation on the façades.

As the influence of controls of internal blinds on cooling consumption is strongly linked to building characteristics, there is a need to inform occupants about how their actions influence the building performance. In this regard, Yao (2014) stated that occupant interactions with internal blinds should be improved to better respond to outdoor conditions aiming at reducing energy consumption. Providing guides to control internal blinds or promoting awareness campaigns for occupants may play a role to solve this issue.

The influence of temperature-based control and the impact of internal blinds on the reduction of the amount of time that the setpoint temperature is not met are strongly linked to the HVAC configuration in the EnergyPlus programme. Different systems, such as those with Variable Refrigerant Flow (VRF) technology, could impact on the results in their own way and this influence should be tested in future studies.

\section{Using different finishings in internal blinds}

Figure 4 shows that using different finishings for internal blinds impacted on the confidence intervals and averages of cooling energy consumptions of the cases tested. Further investigation was conducted to understand how different finishings affected the cooling energy consumption according to solar orientation and controls tested.

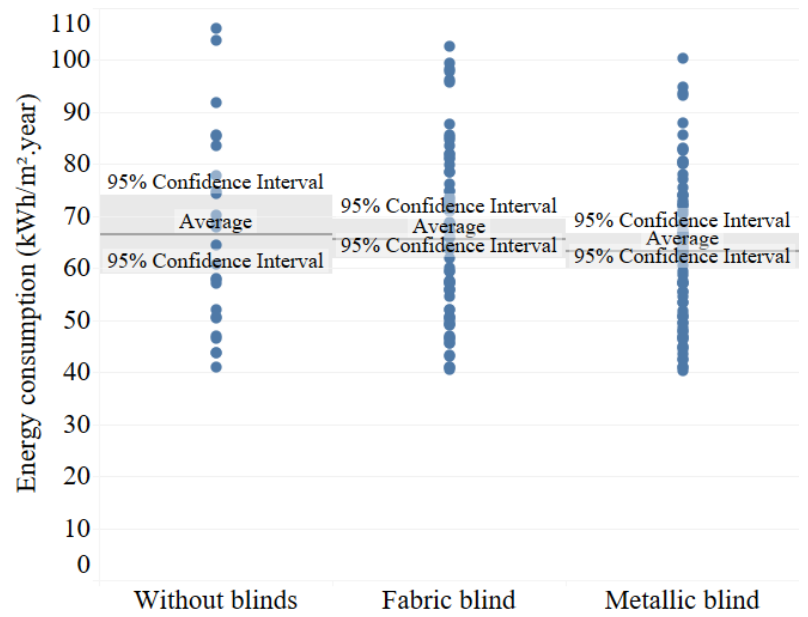

Figure 4: Relation between internal blind finishings and cooling energy consumption.

The cooling energy consumption of spaces was compared case-by-case considering the two finishings. First evidence (see Figure 4) supported that spaces with metallic blinds consume less energy when compared to similar spaces with fabric blinds. In this regard, Figure 5 shows the reduction of cooling energy consumption in the cases tested using metallic blinds compared to fabric blinds.

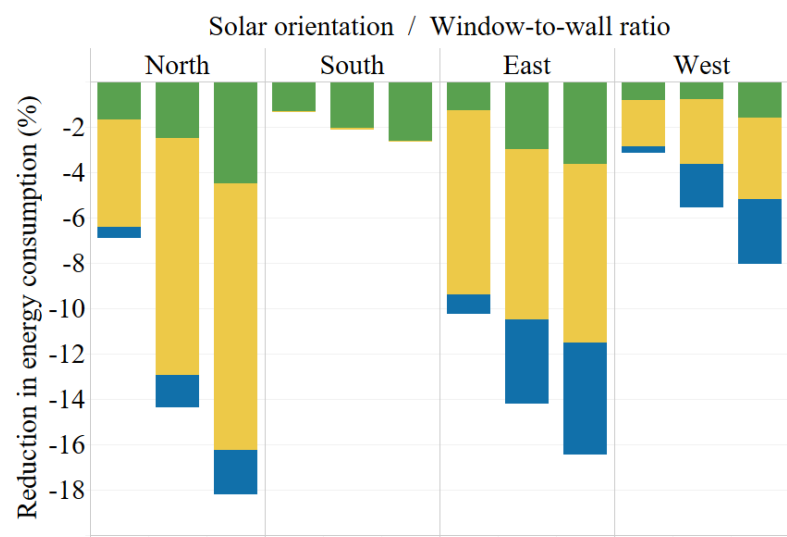

$20 \%$ 50\% 80\% 20\% 50\% 80\% 20\% 50\% 80\% 20\% 50\% $80 \%$

$$
\begin{array}{|l|}
\text { Control of blinds } \\
\text { - Time-based } \\
\text { Solar radiation }
\end{array}
$$$$
\text { - Temperature }
$$

Figure 5: Reduction in cooling energy consumption of spaces with metallic blinds in relation to fabric blinds.

It is important to notice that the influence of metallic blinds on the cooling energy consumption is related to both building characteristics and control patterns. The most influenced by the external conditions (i.e., a window-to-wall ratio equal to $80 \%$ ), the most impactful is the change in the finishing of internal blind - see variations between east and south-oriented spaces. Similarly, to the overall consumption, changing fabric blinds to metallic blinds was more effective for north and east-oriented spaces. Metallic blinds were responsible for reducing up to $12 \%$ of cooling energy consumption 
compared to fabric blinds when solar-radiation-based control was adopted; up to $5 \%$ with time-based control; and up to $4 \%$ with temperature-based control.

As the solar radiation is low in south-oriented spaces the control of internal blinds triggered by solar radiation had no remarkable result. In this case, the changing in finishing was more impactful when internal blinds have temperature-based control.

The simulation results have proved that using internal blinds reduce the cooling energy consumption of buildings and that different finishings have different outcomes. Thus, it was tested if different internal blind finishings and controls influence the amount of time that the setpoint is not met during working hours compared to the cases without blinds. Figure 6 shows the results of this analysis. Similarly to the cooling energy consumption, the reduction of the amount of time that the setpoint temperature is not met during working hours is related to the window-to-wall ratio of spaces. Thus, the larger the windows are, the more effective the internal blinds are for the indoor thermal conditions.

Regarding the influence of different finishings on the reduction of the amount of time that the setpoint temperature is not met during working hours, it is important to notice that the control of blinds has unlikely impacts for different finishings tested. Temperature-based controls impact more the spaces with metallic blinds (up to $70 \%$ of reduction), while solar-radiation-based controls are impactful for spaces with fabric blinds (up to 50\%). This may be due to both the conductivity and transmittance of those materials. As metallic blinds have higher conductivity and lower transmittance, temperature-based control may trigger internal blinds closing in moments with low solar radiation, which reduces the overheating of blind slats while blocking diffuse radiation. On the other hand, fabric blinds have much lower conductivity and may not overheat even when there is high direct radiation incidence. This difference in the superficial temperature may influence the radiant temperature of the space, which impacts the indoor operative temperature. As shown by Bessoudo et al. (2010), the use of internal blinds can boost indoor thermal conditions as they improve the operative temperature and reduce radiant asymmetry.

The decrease in the amount of time that the setpoint temperature is not met during working hours improves indoor thermal conditions. Such improvements may reduce the thermal discomfort of occupants. D'Oca et al. (2018) concluded that office workers consider easier to share control of internal blinds and shades than thermostat settings. Thus, this finding provides a solution to improving indoor thermal conditions without bothering occupants. It is important for occupants to be aware of how human-system interactions impact the performance of buildings. Such awareness can play an important role and boost performance levels during the operation phase of building life cycle.

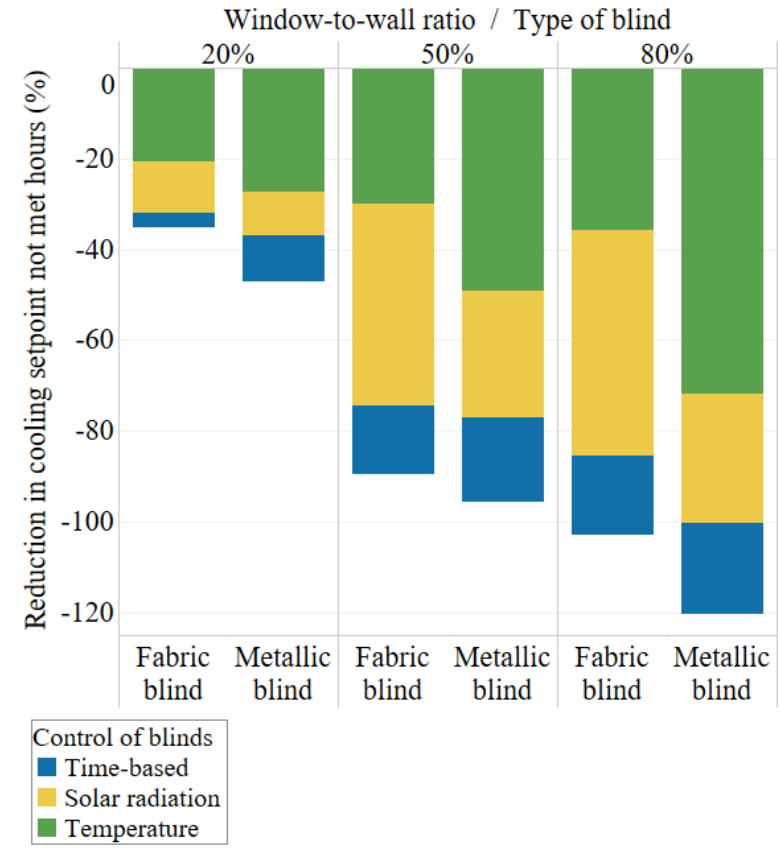

Figure 6: Variation in the amount of time that the setpoint temperature is not met during working hours compared to spaces without blinds.

The results found support the concept presented by D'Oca et al. (2018) that the human dimension of energy consumption in buildings is important for different stakeholders throughout the building life cycle. Results shown herein can inform building designers about the best options regarding internal blinds (both automation controls and finishings); operators and managers can improve the systems already used in buildings by changing some materials or adapting the way they are controlled; and occupants can be informed about to what extent their behaviours influence building energy performance, aiming at boosting performances by increasing occupant awareness.

\section{Generalization of this study}

The outcomes presented are strongly linked to the climate of Florianópolis, location and culture. Considering different cities in Brazil (e.g., where latitudes are near zero), the reported period when blinds are closed could be different: users in south-oriented spaces probably close internal blinds throughout the year more frequently than users do in Florianópolis. Moreover, considering users in totally different climate and culture (such as northern America or Europe) may impact even more the results.

Thus, a cross-location assessment should be important to understand and compare outcomes. Regarding user behaviour in buildings, a framework and a cross-country survey was proposed by D'Oca et al. (2017) and was included as one of the main findings in the final report of the Annex 66 (Yan and Hong, 2018). Similar evaluations may be done in different locations through a low-cost framework structured in Figure 7. Although a simple approach, this proposal can improve design practices in developing countries, where data from smart meters and building sensors to understand user behaviour are hardly available. For different locations, researchers and 
building designers may test combinations of controls and finishings of internal blinds similarly to what has been done in this study. Valuable insights regarding the choice of appropriate controls and finishings to improve indoor conditions according to the local climate can be reached.

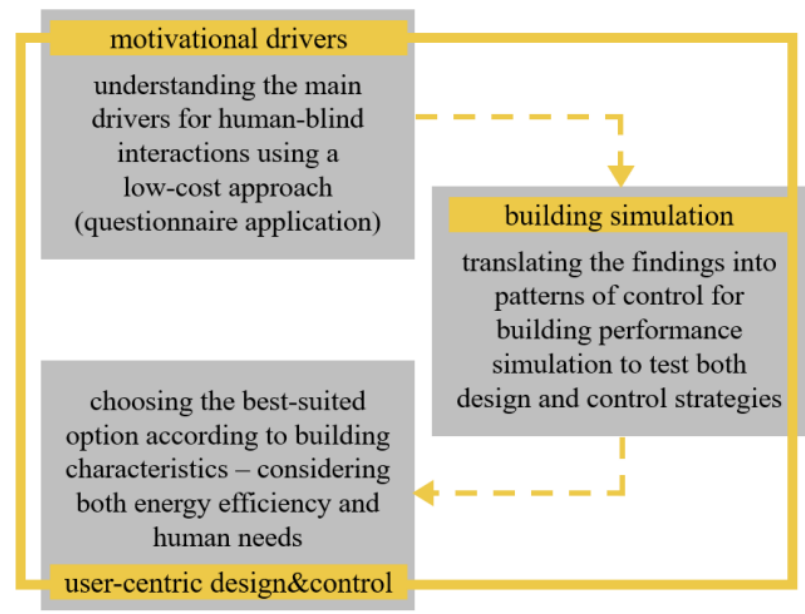

Figure 7: Proposed framework to apply the method in different locations.

\section{Conclusion}

This paper has shown the influence of controls and finishings of internal blinds on the cooling energy consumption of spaces with different building characteristics located in Florianópolis - southern Brazil. Three control patterns were configured according to occupant self-reported stimuli that trigger adjustments of internal blinds. Controls based on rules regarding time, indoor temperature and solar radiation on windows were tested. Such controls were compared to scenarios with no internal blinds. Moreover, both fabric and metallic internal blinds were tested and all the variations were combined to different building characteristics such as solar orientation, window-to-wall ratio and width-todepth ratio. Building performance simulations were conducted using the EnergyPlus computer programme. This paper addresses the following noteworthy outcomes:

(a) Influences of controls of internal blinds are related to building characteristics: the most the building is influenced by the exterior conditions, the most it is impacted by different control strategies. In this aspect, controls of internal blinds have mostly impacted spaces with a window-to-wall ratio equal to $80 \%$, width-to-depth ratio equal to $1: 1$ and both north and east solar orientations. This outcome supports the idea that designing robust buildings is a possible solution to reduce the discrepancies between expected and real energy consumption during building operation;

(b) Solar-radiation-based control was the most important strategy for reducing cooling energy consumption in the north, east and west-oriented spaces. For the southoriented ones, temperature-based control was the most impactful as this orientation is the lesser influenced by direct solar radiation throughout the year;

(c) Metallic blinds result in less cooling energy consumption than fabric blinds. Considering both the average of all cases tested and the averages grouped according to building characteristics, metallic blinds reduced the cooling energy consumption. Greater reductions were obtained for solar-radiation-based control in north, east and west-oriented spaces;

(d) The amount of time that the setpoint temperature is not met during working hours was reduced when internal blinds were used compared to the "without blinds" scenario. This is an important finding as it suggests that a less disturbing interaction (adjustment of blinds) can impact the indoor thermal environment and reduce the necessity of more bothering interactions (adjustments of thermostats);

(e) Associations of controls and finishings of internal blinds had contrasting outcomes on the amount of time that the setpoint temperature is not met during working hours. Temperature-based control was most effective when metallic blinds were used, while solar-radiationbased control had better results for fabric blinds. This outcome is due to the thermal properties of each material, and this information can be used during building design processes to improve indoor thermal conditions at the operation phase.

Although many strategies for controlling internal blinds have reduced the cooling energy consumption, combinations of strategies may have more impact on the energy performance of buildings. This solution could solve problems like: a temperature-based control does not close the blinds during winter even when occupants suffer from visual discomfort caused by excessive solar radiation; or a solar-radiation-based control opening the blinds when occupants would still keep them closed due to the high indoor temperature. Thus, in a real-world scenario, these controls can learn from occupant adjustments and enhance both better energy efficiency and indoor quality levels as shown by Gunay et al. (2013). Future studies will focus on using Energy Management Systems in EnergyPlus to test the influence of combined strategies on the building performance.

\section{Acknowledgement}

The authors would like to thank the Brazilian governmental agency CAPES (Fundação Coordenação de Aperfeiçoamento de Pessoal de Nível Superior), for the financial support to develop this study.

\section{References}

Bavaresco, M.V. and Ghisi, E. (2018). Influence of user interaction with internal blinds on the energy efficiency of office buildings. Energy and Buildings $166,538-549$.

Bessoudo, M., Tzempelikos, A., Athienitis, A. and Zmeureanu, R. (2010). Indoor thermal environmental conditions near glazed facades with shading devices Part I: experiments and building thermal model. Building and Environment 45, 2506-2516.

Brazilian Center for Energy Efficiency in Buildings CB3E. (2017). Proposal for a method for assessing energy efficiency based on primary energy of buildings $(R T Q-C)$. (in PT). 
Brazilian Health Regulatory Agency - ANVISA (2003). Resolution number 9, 16 January 2003. (in PT).

Buso T., Fabi V., Andersen R.K. and Corgnati S.P. (2015). Occupant behaviour and robustness of building design. Building and Environment 94, 694703.

D'Oca, S., Chen, C.F., Hong, T. and Belafi, Z. (2017). Synthesizing building physics with social psychology: An interdisciplinary framework for context and occupant behavior in office buildings. Energy Research \& Social Science 34, 240-251.

D’Oca, S., Pisello, A.L., Simone, M., Barthelmes, V.M., Hong, T. and Corgnati, S.P. (2018). Human-building interaction at work: Findings from an interdisciplinary cross-country survey in Italy. Building and Environment 132, 147-159.

D'Oca, S., Hong, T. and Langevin, J. (2018). The human dimensions of energy use in buildings: A review. Renewable and Sustainable Energy Reviews 81, 731742.

Frontini, F. and Kuhn, T. (2012). The influence of various internal blinds on thermal comfort: A new method for calculating the mean radiant temperature in office spaces. Energy and Buildings 54, 527-533.

Gaetani, I., Hoes P.J. and Hensen, J.L.M. (2016). Occupant behavior in building energy simulation: Towards a fit-for-purpose modeling strategy. Energy and Buildings 121, 188-204.

Ghisi, E., Tinker, J.A. and Ibrahim, S.H. (2005). Área de janela e dimensões de ambientes para iluminação natural e eficiência energética: literatura versus simulação computacional. Ambiente Construído (Online) 5, 81-93. (in PT).

Gunay, H.B., O’Brien, W. and Beausoleil-Morrison, I. (2013). A critical review of observation studies, modeling, and simulation of adaptive occupant behaviors in offices. Building and Environment 70, 31-47.

Haldi F. and Robinson, D. (2008). On the behaviour and adaptation of office occupants. Building and Environment 43, 2163-2177.

Haldi F. and Robinson, D. (2010). Adaptive actions on shading devices in response to local visual stimuli. Journal of Building Performance Simulation 3, 135153.

Hong, T., Taylor-Lange, S.C., D'Oca, S., Yan, D. and Corgnati, S.P. (2016). Advances in research and applications of energy-related occupant behavior in buildings. Energy and Buildings 116, 694-702.

Hong, T., Yan, D., D'Oca, S. and Chen, C. (2017). Ten questions concerning occupant behavior in buildings: The big picture. Building and Environment 114, 518530.

Kirimtat, A., Koyunbaba, B.K., Chatzikonstantinou, I., Sariyildiz, S. (2016). Review of simulation modeling for shading devices in buildings. Renewable and Sustainable Energy Reviews 53, 23-49.

Kuhn, T.E., Bühler, C. and Platzer, W.J. (2001). Evaluation of overheating protection with sun-shading systems. Solar Energy 69, 59-74.

Laboratory of Energy Efficiency in Buildings - LabEEE. (2016). Weather files INMET 2016. Available at: <http://www.labeee.ufsc.br/downloads/arquivosclimaticos/inmet2016>. (in PT).

Mahdavi, A., Mohammadi, A., Kabir, E. and Lambeva, L. (2008). Occupants' operation of lighting and shading systems in office buildings. Journal of Building Performance Simulation 1, 57-65.

National Institute of Metrology, Quality and Technology - INMETRO. (2018). National Energy Conservation Label. Available at: <http://www.inmetro.gov.br/consumidor/pbe/condici onadores_ar_split_hiwall_indicenovo.pdf >. (in PT).

O'Brien, W. (2013). Occupant-proof buildnigs: can we design buildings that are robust against occupant behavior? Proceedings from BSO2013: Conference of International Building Performance Simulation Association. Chambéry (FR), 26-28 August 2013.

O'Brien, W. and Gunay, H.B. (2015). Mitigating office performance uncertainty of occupant use of window blinds and lighting using robust design. Building Simulation 8, 621-636.

O'Brien, W., Kapsis, K. and Athienitis, A.K. (2013). Manually-operated window shade patterns in office buildings: A critical review. Building and Environment 60, 319-338.

Reinhart, C.F. and Niemasz, J. (2018). Diva for Rhino Environmental Analysis for Buildings. Abvailable at: <http://diva4rhino.com/user-guide>.

U.S. Department of Energy - DOE. (2018). Input Output Reference: The Encyclopedic Reference to EnergyPlus Input and Output. Lawrence Berkeley National Laboratory.

Yan D., O'Brien, W., Hong, T., Feng, X., Gunay, H.B., Tahmasebi, F. and Mahdavi, A. (2015). Occupant behavior modeling for building performance simulation: Current state and future challenges. Energy and Buildings 107, 264-278.

Yan, D. and Hong, T. (2018). Definition and Simulation of Occupant Behavior in Buildings - Annex 66 Final Report. International Energy Agency.

Yao, J. (2014). Determining the energy performance of manually controlled solar shades: A stochastic model based co-simulation analysis. Applied Energy 127, 64-80.

Yoshino, H., Hong, T. and Nord, N. (2017). Total energy use in buildings - Analysis and evaluation methods. Energy and Buildings 152, 124-13. 